\title{
NEBULIZED KETAMINE IN A PEDIATRIC PATIENT WITH SEVERE ASTHMA EXACERBATION
}

\author{
N. Djobbi, H. Besbes, S. Bouguerra, O. Maatouk, A. Chaabane, C. Chouchane, S. Chouchane .
}

faculty of medecine of monastir-universiy of monastir, peadiatric, Tunisia.

\section{Background and Aims :}

Asthma is a major cause of morbidity and mortality despite advances in outpatient treatment. Sometimes, children fail to respond to standard treatment and can potentially require mechanical ventilation

\section{Case report :}

A 3 years-old-boy with Prader willi syndrome was admitted in the peaditric intensive care unit (ICU) for respiratory distress and wheezing.

He had a medical history of remarkable episodes of acute wheezing at aged 8 and 12 months.

On admission, the patient displayed marked accessory muscle use and had an oxygen saturation of $90 \%$.

He received many doses of terbutaline $2 \mathrm{mg}$ and ipratropium bromide $250 \mu \mathrm{g}$ for an hour duration via a nebulizer device, as well as intramuscular Dexaméthasone $(0.2 \mathrm{mg} / \mathrm{Kg})$.

He had become less responsive; oxygen saturation was only $92 \%$ on high-flow oxygen $(10 \mathrm{l} / \mathrm{min})$. Arterial blood gases showed $\mathrm{pH} 7.29 ; \mathrm{pCO} 2=9 \mathrm{Kpa}$ and $\mathrm{pO} 2=92$. mmhg .

We decided to attempt ketamine nebulization $(1 \mathrm{mg} / \mathrm{kg})$ as a last resort concomitantly with preparing the patient for a possible intubation.

Twenty minutes after, the patient's respiratory status markedly improved, minimally audible wheezing on chest auscultation and oxygen saturation level increased to $98 \%$.

Blood gas analysis showed marked improvement: $\mathrm{pH}$ of 7.33,pCO2 of $5 \mathrm{Kpa}$ and pO2 of $100 \mathrm{mmhg}$.

He did not experience any exacerbation overnight and was discharged from ICU 12 hours later.

\section{Conclusion:}

The uncommon use of nebulized ketamine in this case indicates that this route might be a promising option in the management of severe asthma exacerbation in children.

\section{Discussion :}

- Children are frequently admitted for acute asthma exacerbation in the emergency department.

- In some cases, standard regimens treatment fails and mechanical ventilation is required.

- ketamine IV for the treatment of severe asthma exacerbation has been shown in case reports and observational studies to improve outcome and preventing mechanical ventilation [1-3].

- Nebulized ketamine have suggested that this route of use is both effective and plausible for various situations [5-8]

- Advantages include rapid delivery and absorption into the systemic circulation and the possibility of administration without the need of IV access line.

- However, the use of nebulized ketamine for treatment of asthma in humans has never been investigated.

- In a murine model of reactive airway disease, Zhu et al. studied the effect of ketamine inhalation on bronchial hyperresponsiveness and airway inflammation.

- As confirmed by lung histological examination, Th2 cytokine levels and total and differential cell counts in the broncho-alveolar lavage fluid, it was demonstrated that nebulized ketamine inhibits the cascade of inflammation and reduces markers of inflammation [9].

- It is also plausible that the systemic effect of ketamine induced anxiolysis and a decrease in the mechanical load breathing without compromise of the respiratory drive.

- In our case, Ketamine may have provided time for standard therapies to take effect, and thereby obviate intubation

\section{References:}

[1] Shlamovitz GZ, Hawthorne T. Intravenous ketamine in a dissociating dose as a temporizing measure to avoid mechanical ventilation in adult patient with severe asthma exacerbation. J Emerg Med. 2011;41:492-4

[2] Denmark TK, Crane HA, Brown L. Ketamine to avoid mechanical ventilation in severe pediatric asthma. J Emerg Med. 2006;30:163-6.

[3] Kiureghian E, Kowalski JM. Intravenous ketamine to facilitate noninvasive ventilation in a patient with a severe asthma exacerbation. Am J Emerg Med. 2015;33(11):1720.e1-2.

[4] Lau TT, Zed PJ. Does ketamine have a role in managing severe exacerbation of asthma in adults? Pharmacotherapy. 2001;21:1100-6.

[5] Elhefny RA, Elsonbaty M, Nassib S, Mansour M. Is this the time to introduce ketamine in acute respiratory distress syndrome? A pilot study. Egypt J Cardiothorac Anesth 2015;9:23-8
[6] Ahuja V, Mitra S, Sarna R. Nebulized Ketamine decrease incidence and severity of post-operative sore throat. Indian J Anaesth. 2015;59(1):37-42. [7] Zanaty OM, El Metainy SA. A comparative evaluation of nebulized dexmedetomidine, nebulized ketamine, and their combination as premedication for outpatient pediatric dental surgery. Anesth Analg. $2015 \mathrm{Jul} ; 121$ (1):167-71 [8] Elkoundi A, Bensghir M, Lalaoui SJ. Nebulized ketamine for successful management of difficult airway. J Clin Anesth. 2017;41:71-2.

[9] Zhu MM, Zhou QH, Zhu MH, Rong HB, Xu YM, Qian YN, et al. Effects of nebulized ketamine on allergen-induced airway hyperresponsiveness and inflammation in actively sensitized Brown-Norway rats. J Inflamm (Lond) 2007;4:10. 